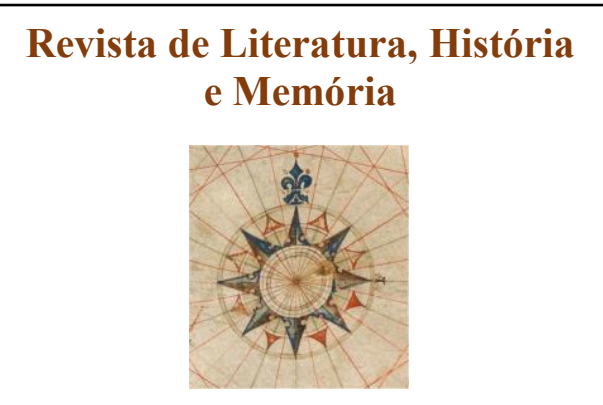

Dossiê: Feminismos e literaturas

ISSN 1983-1498

VOL. 17 - No 30 - 2021

U N I O E S T E / CA S C A V E L - p. 159-175

\title{
AUDRE LORDE: CONTRIBUIÇÕES PARA UMA EPISTEMOLOGIA DA CRÍTICA FEMINISTA À LITERATURA LÉSBICA NEGRA
}

Audre Lorde: contributions to an epistemology of feminist literary criticism of black lesbian literature

Alina Nunes ${ }^{1}$

RESUMO: Este artigo explora a possibilidade da construção de uma epistemologia da crítica feminista à literatura lésbica negra através da obra de Audre Lorde. A partir das contribuições de Elaine Showalter, Adrienne Rich e Conceição Evaristo, exploro as ideias da zona selvagem, do sonho de uma língua em comum, do continuum lésbico e da escrevivência, alinhando esses conceitos ao que foi escrito por Audre Lorde em ensaios escritos na década de 1970. Nesse sentido, discuto a ideia do erótico como potência para a escrita e a escrevivência como estratégia de esperança. Essas ideias são importantes para a construção de uma epistemologia da literatura lésbica negra, que, assim como Audre Lorde fez em sua obra, alinhe a vida à escrita e a teoria à poesia.

PALAVRAS-CHAVE: Audre Lorde; Crítica feminista; Literatura lésbica negra.

ABSTRACT: This essay explores the possibility of building an epistemology for feminist literary criticism of black lesbian literature through Audre Lorde. Based on the contributions of Elaine Showalter, Adrienne Rich and Conceição Evaristo, I explore the ideas of the wild zone, the dream of a common language, the lesbian continuum and escrevivência, aligning these concepts with what was written by Audre Lorde in her essays written in the 1970s. Thus, I discuss the idea of the erotic as power and escrevivência as a strategy of hope. These are important to the construction of an epistemology of black lesbian literature, which, as Audre Lorde did in her work, aligns life with writing and theory with poetry.

KEYWORDS: Audre Lorde; Feminist literary criticism; Black lesbian literature.

\section{CONSIDERAÇÕES INICIAIS}

Minha sexualidade é parte integrante de quem eu sou, e minha poesia vem da intersecção entre mim e meus mundos.

- Audre Lorde ${ }^{2}$

Audre Lorde foi uma educadora e poeta negra, lésbica, feminista, mãe de dois filhos, nascida nos Estados Unidos em 1934, filha de pais imigrantes caribenhos vindos de Barbados

\footnotetext{
1 Mestranda em História pelo Programa de Pós-Graduação em História da Universidade Federal de Santa Catarina (PPGH/UFSC), bolsista FAPESC. Graduada em Bacharelado e Licenciatura em História pela mesma instituição. (UFSC). É vinculada ao Laboratório de Estudos de Gênero e História (LEGH/UFSC). Email: alinanunes2@gmail.com.

2 Tradução minha. No original: "My sexuality is part and parcel of who I am, and my poetry comes from the intersection of me and my worlds" (ROWELL; LORDE, 2000).
} 
e Granada. Ela publicou 15 livros de poesia, um romance, vários ensaios e entrevistas. Em sua escrita, sempre afirmou ser possível conciliar poesia e teoria, escrevendo a partir das particularidades de suas vivências cotidianas como uma mulher "negra, lésbica, mãe, poeta e guerreira", como ela mesma constantemente se definia. Neste texto, busco reflexões sobre três ensaios de Audre Lorde, traduzidos e publicados no livro "Irmã Outsider: Ensaios e Conferências" (2020a): "A poesia não é um luxo", escrito em 1977, “A transformação do silêncio em linguagem e ação", também escrito em 1977 e "Os usos do erótico: o erótico como poder", escrito em 1978. Objetivo perceber a importância dos escritos de autoria de Audre Lorde na construção de uma epistemologia para uma crítica feminista da literatura lésbica negra.

Antes de tudo, é importante pensarmos algumas definições sobre literatura de mulheres, literatura lésbica e literatura lésbica negra. Dentro dos debates do campo da crítica feminista da literatura, há uma questão bastante recorrente que diz respeito à construção e à terminologia de um campo específico da literatura relacionado à "escrita feminina" ou "literatura feminina". A questão envolvendo essas nomenclaturas indaga quais textos estariam dentro desse campo, se o campo seria referente às leitoras ou às autoras, ou até mesmo inquirindo a definição do que é "feminina" ou "feminino" (PONTES, 2018). Os debates em torno dessas terminologias são paradoxais, pois, se por um lado essas nomenclaturas por vezes são vistas como essencialistas ou reducionistas, por outro é importante que existam terminologias para agrupar a literatura de sujeitos que foram invisibilizados pelos cânones.

Entre definições psicanalíticas e biologizantes da literatura de mulheres, ou de uma écriture feminine pensada pela crítica feminista francesa nos anos 1970, em seu clássico texto “A crítica feminista no território selvagem", Elaine Showalter (1994) traça um panorama para um modelo cultural de escrita das mulheres. Esse texto, publicado pela primeira vez em 1981, foi um marco para a crítica e teoria literária, reivindicando uma base teórica para a crítica feminista que reafirmava a autoridade da experiência das mulheres. $\mathrm{O}$ modelo cultural leva em consideração que as mulheres se encontram dentro da cultura geral, definida pelos homens, mas são restringidas e silenciadas pelo patriarcado quando tentam existir plenamente dentro dessa cultura. É essa cultura geral que estabelece, inclusive, o modelo literário autorizado, no qual as mulheres dificilmente se encaixam. Entretanto, as mulheres conseguem transformar essa repressão e a redefinem, criando uma cultura "de mulheres", que não é acessada pelos homens. Para a autora, uma vantagem da utilização do modelo da cultura das mulheres para a crítica feminista é que ele pode demonstrar como "a tradição feminina pode ser uma fonte positiva de força e solidariedade, bem como fonte negativa de impotência; ele 
pode gerar suas próprias experiências e símbolos que não sejam simplesmente o obverso da tradição masculina" (SHOWALTER, 1994, p. 53). Buscando fundamentar esse modelo cultural da escrita das mulheres, Showalter propõe que "uma crítica feminista agressiva deve [...] ver a escrita das mulheres em sua relação histórica e cultural variável com aquele outro corpo de textos identificados pela crítica feminista não simplesmente como literatura, mas como "escrita dos homens"." (SHOWALTER, 1994, p. 50). Sendo assim, só é possível entender a diferença da escrita das mulheres a partir de um olhar que leve em conta relações culturais complexas historicamente fundamentadas.

Dentro desse modelo cultural da escrita das mulheres, proponho uma reflexão sobre a literatura lésbica, pois se a literatura de mulheres não pertence à cultura geral, a literatura de mulheres lésbicas é ainda mais invisibilizada. A literatura lésbica não carrega consigo uma única e exata definição, mas gostaria de propor que refletíssemos sobre essa literatura de acordo com o que afirma Vanessa Cerqueira (2021): "uma escrita que aborda a lesboafetividade, uma crítica à heteronormatividade, bem como às vivências e ao amorresistência, amor de mulheres" (CERQUEIRA, 2021, p. 437). Para a autora, "o espaço literário ainda é excludente, privilegia discursos da sociedade heteropatriarcal, e há uma imensa dificuldade de publicação, circulação e visibilidade de livros que tragam em seu enredo personagens/histórias lésbicas que não sejam erotizadas ou estereotipadas." (CERQUEIRA, 2021, p. 437). Por isso, a literatura lésbica habita o mundo subalterno da literatura (CERQUEIRA, 2021).

A estereotipação e erotização de histórias lésbicas é uma das faces da instituição heterossexualidade compulsória. Junto a esse aspecto, estão tantos outros que afirmam a heterossexualidade como única opção para mulheres. Em contrapartida, Adrienne Rich (2010) denota a importância da construção de vínculos entre mulheres a partir do que define como "continuum lésbico". A autora considera que este continuum é formado por experiências de identificação entre mulheres, sendo a existência lésbica, historicamente invisibilizada e interdita de memória, a marca da ruptura com a heterossexualidade compulsória ( $\mathrm{RICH}, 2010$ ). O continuum lésbico é um conceito que se refere ao conjunto de experiências entre mulheres sem que exista necessariamente uma relação romântica ou desejo sexual entre elas. Rich (2010) considera a possibilidade de que todas as mulheres existam conectadas em um continuum - por isso, todas nós, mulheres, nos movemos "para dentro e para fora desse continuum, mesmo se não nos identificamos como lésbicas” (RICH, 2010, p. 38). Quando as mulheres resistem juntas, o continuum lésbico pode ser pensado como o local onde elas se conectam e se identificam, transformando essas conexões em amizade e amor. Nesse sentido, 
proponho levarmos em consideração o continuum lésbico como um lugar-não-lugar possível para a escrita de uma literatura que valorize o amor entre mulheres: uma literatura lésbica.

Monalisa Gomyde (2021), em seu artigo intitulado "Existe uma cultura literária lésbica?", responde à pergunta que dá título ao seu texto argumentando e demonstrando historicamente que sim, existe uma cultura literária lésbica. Segundo a autora, a cultura literária lésbica "explora a conexão entre criatividade e sexualidade, mas rompe com a concepção da imaginação e da criação da cultura patriarcal” (GOMYDE, 2021, p. 443). Monalisa ainda argumenta que a cultura literária lésbica não concerne somente às mulheres lésbicas, mas constrói possibilidades éticas e estéticas para todas as mulheres que buscam construir uma mudança profunda no mundo patriarcal, até porque " $[\mathrm{u}] \mathrm{m}$ mundo no qual mulheres lésbicas e o amor entre mulheres são a medida é um mundo radicalmente livre para todas." (GOMYDE, 2021, p. 444).

E onde estão as mulheres lésbicas negras? Há uma literatura lésbica negra? Há uma epistemologia lésbica negra? Se, à luz dos grandes cânones, a literatura negra, muitas vezes, não é legitimada como literatura, menos ainda é a produção de mulheres negras lésbicas. Esse apagamento repercute na construção das identidades de mulheres negras lésbicas, que, por não serem representadas na literatura e em tantos outros espaços, sentem-se desumanizadas (DA LUZ et al., 2019, p. 136). Nesse sentido, as autoras Agatha da Luz, Juliana de Miranda e Aiana Silva (2019) afirmam que "a literatura negra lésbica, além de ser uma grande ferramenta de luta, pode trabalhar a humanização desses sujeitos, sob a perspectiva de gênero, lesbianidade e raça" (DA LUZ et al, 2019, p. 141). Por isso,

a literatura negra lésbica é um dos instrumentos de emancipação desses afetos/vivências, ao identificar a possibilidade de mulheres negras lésbicas serem vistas como vidas em movimento que, por vezes, se permitem constelar, amar, ser amada e romper com a marca ancestral da solidão que é carregada na intergeracionalidade; e estes demarcadores se constroem como representações para aquelas que estão a chegar. A representatividade negra lésbica é urgente, por isso a escrita de mulheres negras lésbicas é tão necessária para o desenvolvimento de uma identificação e pertencimento, relevante para a quebra do não-lugar e a construção de uma nova narrativa de humanização desses corpos-sujeitos (DA LUZ et. al., p. 141).

Quando falamos sobre o apagamento da literatura lésbica negra, ele não é sinônimo de inexistência. O que deve ser pautado é que essa literatura e suas epistemologias não são acessadas da mesma maneira que as epistemologias produzidas por mulheres brancas heterossexuais (DA LUZ et al, 2019, p. 136). Nesse sentido, Audre Lorde se posicionava justamente como uma "irmã outsider": uma irmã forasteira, intrusa, estrangeira aos cânones 
brancos e heterossexuais da literatura. Assim, apontar e explorar a potência da escrita para mulheres lésbicas negras é ampliar o escopo da resistência dessas mulheres, já que, nesse aspecto, é muito difícil separar a literatura da própria vida. De acordo com a própria Audre Lorde, em entrevista para Charles Rowell na revista Callaloo em 1990: "Minha sexualidade é parte integrante de quem eu sou, e minha poesia vem da intersecção entre mim e meus mundos" (ROWELL; LORDE, 2000, tradução minha). A obra de Audre Lorde registra sua materialidade enquanto mulher, negra, lésbica, mãe, poeta e guerreira, contribuindo para uma epistemologia da literatura lésbica negra.

Nesse artigo, não procuro responder às problemáticas nem resolver os debates em torno das nomenclaturas "literatura feminina", "literatura lésbica" ou "literatura lésbica negra". Entretanto, levo-os em consideração ao propor uma reflexão sobre as bases epistemológicas para uma literatura de mulheres lésbicas negras ${ }^{3}$, pensando que essa nomenclatura pode melhor articular a presença dessas mulheres que resistem à invisibilização normalmente imposta. Na primeira e na segunda parte do artigo, através de Adrienne Rich e seu "sonho de uma língua em comum" (CAMARGO, 2018), elaboro sobre a "zona selvagem" de Elaine Showalter e as possibilidades dos usos do erótico de Audre Lorde para a escrita lésbica feminista, percebendo o continuum lésbico e o amor entre mulheres como práticas importantes para o registro da memória e história lésbica. Na terceira parte, busco articular a escrevivência como uma prática de resistência através dos ensaios de Audre Lorde.

\section{CAMINHANDO PELA ZONA SELVAGEM E SONHANDO UMA LÍNGUA EM COMUM}

Os debates sobre a linguagem foram centrais na constituição de vários aspectos da teoria e crítica literária feminista. Algumas autoras, como Monique Wittig (2019) ou Adrienne Rich (1971) apontaram problemáticas na utilização da "linguagem do opressor". Entretanto, para Elaine Showalter (1994, p. 35), “o problema vai muito além dos esforços reformistas em purificar a linguagem de seus aspectos sexistas". Apesar de considerar que a defesa de uma linguagem das mulheres é um importante gesto político, a autora aponta que "o conceito de uma linguagem das mulheres está crivado de dificuldades" (SHOWALTER, 1994, p. 38). Ela reconhece que "a literatura das mulheres ainda é assombrada pelos fantasmas da linguagem reprimida" (SHOWALTER, 1994, p. 39), mas afirma que não é na estrutura da linguagem que

\footnotetext{
${ }^{3}$ A escolha de Audre Lorde, uma mulher nascida nos Norte Global, como objeto deste artigo, não diminui a importância das escritoras lésbicas negras brasileiras na contemporaneidade. Algumas destas escritoras são Cidinha da Silva, Miriam Alves, Bárbara Esmenia e Tatiana Nascimento.
} 
devemos basear nossa crítica feminista. Assim, ela aponta que

\begin{abstract}
A tarefa apropriada para a crítica feminista, acredito eu, é concentrar-se no acesso das mulheres à língua, no campo lexical disponível a partir do qual as palavras podem ser selecionadas, nos determinantes de expressão ideológicos e culturais. O problema não é que a língua seja insuficiente para expressar a consciência das mulheres, mas é que foi-lhes negada a totalidade dos recursos da língua e elas foram forçadas ao silêncio, ao eufemismo ou ao circunlóquio (SHOWALTER, 1994, p. 39).
\end{abstract}

É nesse sentido que Showalter propõe o modelo cultural da escrita das mulheres. Como já explicado previamente, esse modelo leva em consideração que as mulheres se encontram dentro de uma cultura geral que se pretende universal, definida pelo grupo masculino dominante, mas constituem um grupo silenciado. Contudo, as mulheres não são totalmente contidas pela cultura geral, pois existe uma parte da cultura silenciada que cresce para fora do limite dominante, e, por isso, é uma "zona selvagem". Essa cultura "de mulheres" normalmente não pode ser acessada pelos homens, é estranha a eles. Entretanto,

existe uma zona correspondente da experiência masculina que é estranha às mulheres. Mas, se pensamos na zona selvagem metafisicamente, ou em termos de consciência, não há espaço masculino correspondente, já que tudo na consciência masculina está dentro do círculo da estrutura dominante e, desta forma, acessível à linguagem ou estruturada por ela. [...] as mulheres sabem como é a parte crescente masculina, mesmo se nunca a viram, pois ela se torna o assunto da lenda (como o território selvagem). Mas os homens não sabem o que há no selvagem. (SHOWALTER, 1994, p. 48).

Em vista disso, é na zona selvagem onde pode ser estruturada a linguagem revolucionária das mulheres, que funciona no sentido de expressar aquilo que é silenciado pela cultura dominante, onde é possível escrever fora dos limites impostos pelo patriarcado (SHOWALTER, 1994). Contudo, é importante denotar que não existe escrita ou crítica totalmente fora da estrutura dominante, e por isso as contribuições da "zona selvagem" de Elaine Showalter para uma crítica feminista da literatura lésbica vão no sentido de compreenderem que "na realidade à qual devemos nos dirigir como críticos, a escrita das mulheres é um "discurso de duas vozes" que personifica sempre as heranças social, literária e cultural tanto do silenciado quanto do dominante" (SHOWALTER, 1994, p. 50). A zona selvagem, então, seria o lugar de "uma crítica, uma teoria e uma arte genuinamente centradas na mulher, cujo projeto comum seja trazer o peso simbólico da consciência feminina para o ser, tornar visível o invisível, fazer o silêncio falar" (SHOWALTER, 1994, p. 49).

É na perspectiva de pensar a zona selvagem como o lugar onde é possível subverter a 
cultura universal masculina e verdadeiramente centralizar as mulheres que eu gostaria de localizar a utopia da poeta lésbica Adrienne Rich em seu livro "O Sonho de uma língua comum" (1978), salientando a importância desse texto para a epistemologia da crítica feminista da literatura lésbica. Fazer o silêncio falar, como apontado por Elaine Showalter (1994), é também o objetivo de Adrienne Rich ao propor um "projeto poético que visa romper silêncios seculares e realiza-se constantemente pela consciência da ambivalência do poder da palavra, oscilando entre uso e recusa." (CAMARGO, 2018, p. 58). Ao confrontar o cânone masculino em busca de uma linguagem feminista para narrar o amor entre mulheres, Adrienne Rich recria formas poéticas clássicas em busca da utopia da língua comum, que alinha o político ao poético (CAMARGO, 2018). Rich, assim, "realiza o retrato da afeição entre mulheres, em geral, enquanto continuum ignorado e cerceado historicamente”, e, em contrapartida a essa coerção, "uma linguagem cancelada tremeluz, a todo tempo trazida à tona. O não-dito é evocado, superposto. No ato de escrever, é que se descobre o que não se está dizendo, o com que ainda se embater, o por re-imaginar.” (CAMARGO, 2018, p. 58).

Em se tratando da coexistência da poesia com a teoria feminista, Sarah Camargo (2018) demonstra que "os poemas de Adrienne Rich continuamente complicaram e depuraram sua visada feminista, seu feminismo agindo reciprocamente como teoria resistiva com a qual e contra a qual eles funcionavam. A escrita testa a teoria e lhe resiste." (CAMARGO, 2018, p. 58). Assim, percebemos que há um movimento dialético entre a poesia e a teoria feminista. Podemos observar esse mesmo movimento na obra de Audre Lorde. Nancy Bereano, na introdução do livro "Irmã Outsider", afirma que "a voz de Audre Lorde é central para o desenvolvimento da teoria feminista contemporânea", e que, na obra de Lorde, não existe conflito entre poesia e teoria, esferas que, no pensamento ocidental, são hierarquizadas. ${ }^{4}$ Afinal, "disseram-nos que a poesia tem alma e a teoria tem mente, e que precisamos escolher entre elas", mas, "a escrita de Audre Lorde é um impulso em direção à integridade", pois "de seu desejo de inteireza, de sua necessidade de abranger e abordar todas as partes de si, ela nos ensina sobre o significado de diferença" (BEREANO, 2020, p. 7). Nesse sentido, "a dialética entre produção poética e teoria feminista previne que sua teoria se torne regressivamente ortodoxa e permite à sua poesia ser politicamente efetiva" (CAMARGO, 2018, p. 60). O sonho de uma língua comum diz respeito às mulheres, às poetas e às feministas que habitam dentro de Adrienne Rich, de Audre Lorde e de tantas outras.

\footnotetext{
${ }^{4}$ A hierarquia entre emoção e razão, entre o sentir e o pensar, estrutura o pensamento ocidental. A emoção também tem gênero, pois é supostamente feminina, enquanto a razão é vista como masculina. Os debates em torno dessa temática vêm crescendo nas ciências humanas, mas não poderei me estender sobre isso neste texto. Por isso, sugiro a leitura da introdução do livro de Sara Ahmed (2017).
} 


\section{HABITANDO O CONTINUUM: OS USOS DO ERÓTICO PARA UMA LITERATURA LÉSBICA FEMINISTA}

Em seu ensaio "Heterossexualidade compulsória e existência lésbica", publicado pela primeira vez em 1981, Adrienne Rich (2010) desenvolve duas principais questões: a primeira é o questionamento do porquê a escolha por parte das próprias mulheres de priorizar e amar outras mulheres ter sido invalidada ao longo da história; e a segunda se refere ao apagamento da existência lésbica em uma miríade de textos, inclusive da produção acadêmica feminista. Adrienne Rich afirma que essas questões são resultado da heterossexualidade compulsória, uma instituição que, através do reforço da heterossexualidade, assegura o direito masculino de acesso físico, econômico e emocional às mulheres (RICH, 2010). Um dos principais aspectos que reforça a heterossexualidade compulsória é “deixar invisível a possibilidade lésbica, um continente engolfado que emerge à nossa vista de modo fragmentado de tempos em tempos para, depois, voltar a ser submerso novamente" (RICH, 2010, p. 34). Para Rich, portanto, entender e questionar a heterossexualidade como instituição é um trabalho árduo, mas a recompensa é grande: "uma libertação do pensamento, a exploração de novos caminhos, a dissolução de outro grande silêncio, uma nova claridade nas relações interpessoais" (RICH, 2010, p. 35).

Neste texto, a autora desenvolve a ideia da existência lésbica e do continuum lésbico. Para ela, a "existência lésbica sugere tanto o fato da presença histórica de lésbicas quanto da nossa criação contínua do significado dessa mesma existência” (RICH, 2010, p. 35), enquanto o termo continuum lésbico pode abarcar um conjunto de experiências de identificação e de amor entre mulheres que não necessariamente envolvam o desejo sexual, mas "conexões eróticas femininas". Assim,

Se nós ampliamos isso a fim de abarcar muito mais formas de intensidade primária entre mulheres, inclusive o compartilhamento de uma vida interior mais rica, um vínculo contra a tirania masculina, o dar e receber de apoio prático e político, $[. .$.$] nós começaremos a compreender a abrangência da$ história e da psicologia feminina que permaneceu fora de alcance como consequência de definições mais limitadas, na maioria clínicas, de lesbianismo. A existência lésbica inclui tanto a ruptura de um tabu quanto a rejeição de um modo compulsório de vida. É também um ataque direto e indireto ao direito masculino de ter acesso às mulheres. Mas é muito mais do que isso, de fato, embora possamos começar a percebê-la como uma forma de exprimir uma recusa ao patriarcado, um ato de resistência (RICH, 2010, p. 35-36).

As conexões eróticas femininas que se unem em continuum não se referem ao 
erotismo entendido através do olhar masculino e heterossexual. Adrienne Rich se refere ao erotismo que vai de encontro com o que propõe Audre Lorde no texto "Usos do erótico: o erótico como poder". Segundo Lorde (2020a), o erótico é uma dimensão que habita entre as origens da autoconsciência e o caos dos sentimentos mais intensos, um sentimento profundo de satisfação. O erótico, portanto, é "uma afirmação da força vital das mulheres; daquela energia criativa fortalecida, cujo conhecimento e cuja aplicação agora reivindicamos em nossa linguagem, nossa história, nossa dança, nossos amores, nosso trabalho, nossas vidas." (LORDE, 2020a, p. 57). Nesse sentido, o erótico se contrapõe às tentativas de apagamento da existência lésbica em prol da heterossexualidade compulsória, já que "o que tem sido colocado à parte de nosso conhecimento é a alegria, a sensualidade, a coragem e a comunidade, bem como a culpa, a autonegação e a dor" (RICH, 2010, p. 36).

Para Audre Lorde, o erótico opera de diferentes formas, mas a primeira delas consiste em proporcionar um poder que emana do compartilhamento íntimo de alguma atividade com outra pessoa (LORDE, 2020a). O erótico é considerado por Audre Lorde como a linguagem de resistência para as mulheres. Ela afirma que a rejeição do erótico por parte das mulheres é muito preocupante, justamente "porque não podemos combater o velho poder usando apenas as regras do velho poder. A única forma de fazer isso é criar toda uma outra estrutura que abarque todos os aspectos da nossa existência, ao mesmo tempo que resistimos" (LORDE, 2020a, p. 109). Por isso, em conjunto à definição do continuum lésbico e da ampliação do entendimento da existência lésbica, o erótico pode ser percebido como uma potência na prática da escrita das mulheres. Pois assim

começamos a descobrir o erótico em termos femininos: como ele não é confinado a qualquer parte do corpo ou apenas ao corpo em si mesmo; como uma energia não apenas difusa, mas a ser, tal como Audre Lorde chegou a descrever, onipresente no "compartilhamento de alegria, seja física, seja emocional, seja psíquica” e na repartição de trabalho (RICH, 2010, p. 37).

A ideia do continuum lésbico, portanto, propõe a consolidação de tradição, continuidade e esteio social para as mulheres que amam mulheres, contrapondo-se à destruição de registros e ao apagamento da memória da existência lésbica proposto pela instituição da heterossexualidade. A instituição age, segundo Adrienne Rich, sobretudo atráves "[d]o apagamento da existência lésbica (exceto quando vista como exótica ou perversa) na arte, na literatura e no cinema e [d]a idealização do amor romântico e do casamento heterossexual" (RICH, 2010, p. 26). Por isso, "é possível, então, pensar a formação de um "continuum lésbico" na literatura e em outras formas de expressão enquanto discursos 
em posição de constante resistência, necessários para a própria sobrevivência dos indivíduos considerados dissidentes" (PONTES, 2018, p. 29).

Sara Ahmed (2015), ao destacar a importância dos vínculos feministas, ressalta que a identificação das relações de opressão vividas por mulheres nunca são as mesmas, mas produzem semelhanças entre essas mulheres e, em determinados casos, identificações feministas. Assim, "as histórias de dor podem ser "compartilhadas" somente quando assumimos que elas não são a mesma história, mesmo quando conectadas, e [assim] nos permitem estabelecer vínculos" (AHMED, 2015, p. 263, tradução minha). Referindo-se às mulheres negras e lésbicas, duplamente "outsiders", Adrienne Rich propõe que os vínculos possibilitados pelo continuum lésbico podem ser uma "corda de salvação" (RICH, 2010, p. 41), já que

As mulheres negras têm uma longa tradição de vinculação conjunta [...] em uma comunidade de mulheres negras que tem sido a fonte de informação para a sobrevivência vital e de apoio psíquico e emocional para todas nós. Temos uma cultura folk distinta de mulheres identificadas como negras, baseadas em nossas experiências como mulheres negras em nossa sociedade. Símbolos, linguagem e modos de expressão que são específicos das realidades de nossas vidas. Como raramente as mulheres negras puderam ser incluídas entre os negros e as mulheres que tiveram acesso direto à literatura e outras formas reconhecidas de expressão artística, esta vinculação feminina negra e esta identificação entre mulheres negras acabou por ser frequentemente obscurecida e pouco registrada com exceção das próprias vidas individuais das mulheres negras através das nossas próprias memórias e de nossa particular tradição feminina negra. (BETHEL, 1982, apud RICH, 2010, p. 41).

Nesse sentido é que Adrienne Rich alude à identificação entre mulheres como uma fonte de energia e poder potencial, mas contido pela instituição da heterossexualidade. Para a autora, "a negação da realidade [...] da escolha das mulheres por outras como suas aliadas, companheiras de vida e de comunidade, [...] tem representado uma perda incalculável do poder de todas as mulheres em mudar as relações sociais entre os sexos e de cada uma de nós se libertar" (RICH, 2010, p. 41). Audre Lorde, em “A transformação do silêncio em linguagem e em ação" (2020a), confirma a existência do potencial de poder e energia nas relações entre mulheres que priorizam mulheres, o que podemos aludir à construção do continuum:

As mulheres que me apoiaram durante esse período eram brancas e negras, velhas e jovens, lésbicas, bissexuais e heterossexuais, e todas nós travamos, juntas, uma guerra contra as tiranias do silêncio. Todas me deram a força e o 
acolhimento sem os quais eu não sobreviveria intacta. (LORDE, 2020a, p. 42).

Tendo em vista as contribuições de Elaine Showalter explicitadas acima, acredito ser válido propor que o continuum lésbico se faça na zona selvagem, já que é uma parte da cultura que escapa à cultura patriarcal, ou, mais especificamente, da instituição da heterossexualidade compulsória. O continuum lésbico, então, funciona como um lugar possível para a escrita de uma literatura que descreva o amor entre mulheres, que sonhe com uma língua em comum, um lugar onde é possível o fazer de uma literatura lésbica. Sendo assim, através do erótico como pensado por Audre Lorde, podemos refletir sobre a escrita lésbica feminista, percebendo o continuum lésbico e o amor entre mulheres como práticas importantes para o registro da memória e história da existência lésbica, o que pode contribuir para uma epistemologia da literatura lésbica.

Adrienne Rich (2010) afirma que escolher uma mulher como amante ou companheira diante da heterossexualidade compulsória é um ato político feminista, mas que a existência lésbica só poderá concretizar esse ato político de forma definitiva e libertadora através de uma escolha erótica que se aprofunde através da identificação consciente entre mulheres e com o feminismo lésbico, denotando, mais uma vez, teor político à sua escrita. Nesse mesmo sentido é que Audre Lorde diz: "não existe, para mim, nenhuma diferença entre escrever um bom poema e caminhar sob o sol junto ao corpo de uma mulher que eu amo.” (LORDE, 2020a, p. 61). Para a literatura lésbica, não existe conflito entre teoria, poesia e o amor entre mulheres.

\section{"SEU SILÊNCIO NÃO VAI PROTEGER VOCÊ": A ESCREVIVÊNCIA EM AUDRE LORDE}

No dia 28 de dezembro de 1977, durante o Lesbian and Literature Panel, na Modern Language Association, em Chicago, Audre Lorde apresentou o artigo "A transformação do silêncio em linguagem e em ação". Poucos dias antes, ela havia sido submetida a uma biópsia, que, em 1978, resultaria em um diagnóstico de câncer. Na entrevista de Audre Lorde com Adrienne Rich (LORDE, 2020a), Adrienne relembra que Audre não quis mais apresentar seu texto no painel, pois estava impactada por conta do procedimento cirúrgico. Percebeu, no entanto, que não ter falado sobre aquela experiência era silenciar-se. Audre contou que teve a sensação de que a vida nunca mais seria a mesma, e que ela precisava encarar essa mudança, essa exposição. Audre Lorde conta que sabia que colocar-se em um lugar vulnerável era difícil, mas não fazer isso "seria a pior das mortes" (LORDE, 2020a, p. 114). Para a autora, é 
assim que surge um poema: "no limite, na urgência, não por escolha, mas por necessidade, esse senso de sobrevivência - é daí que o poema surge" (LORDE, 2020a, p. 114).

Uma epistemologia para uma crítica feminista da literatura lésbica negra deve levar em consideração o conceito de "escrevivência", pensado muitos anos depois da entrevista de Audre Lorde, mas que dialoga imensamente com as proposições dessa autora. A escrevivência, escrever a existência, é apresentado por Conceição Evaristo como "a função, a urgência, a dor, a necessidade e a esperança da escrita. É preciso comprometer a vida com a escrita ou é o inverso? Comprometer a escrita com a vida?" (EVARISTO, 2007, p. 17). Esse comprometimento da escrita com a vida é também expressado por Audre Lorde, no artigo "Minha poesia e autodefinição", apresentado no encontro da Modern Language Association, em Nova York, em dezembro de 1976:

Então não posso separar minha vida e minha poesia. Escrevo minha vida e vivo meu trabalho. E encontro verdades que espero sejam capazes de alcançar outras mulheres, de levar riqueza, além das diferenças em nossas trajetórias, as diferenças no amor, no trabalho. Porque é no compartilhamento dessas diferenças que encontramos o crescimento. É no interior dessas diferenças que encontro o crescimento, se for honesta o suficiente para falar de tudo o que sou, de meus amores, rancores, erros, assim como das minhas forças. Sinto, e aposto minha vida e meu modo de vida nisso, que nos fortalecemos quando fazemos aquilo que exige que sejamos fortes (LORDE, 2020b, s/p.).

Assim, podemos perceber que a escrita da Audre Lorde está embebida do que ela é. A escrevivência é a escrita da urgência, da dor, do comprometimento da vida com a escrita - ou o inverso - , e Audre Lorde compromete-se por inteiro em sua escrita. Mesmo que essa não seja uma tarefa fácil, mas que exige força ao mesmo tempo em que fortalece. Para Agatha da Luz, Juliana de Miranda e Aiana Silva (2019), se a literatura é a arte da palavra, quando escrita por mãos negras, “essa arte está para além do estético e do belo, pois estamos falando de uma escrita carregada de vivências, afetos e dores. É uma escrita atravessada, também, por histórias que um dia foram apagadas, silenciadas" (DA LUZ et al., 2018, p. 140). Nesse mesmo sentido, Audre Lorde, em uma entrada de 22 de março de 1984 em seu diário, escreveu: "Relembrei como a poesia pode ser importante na vida de uma comunidade negra comum quando essa produção é realmente a poesia da vida das pessoas que a formam" (LORDE, 2020b, s/p.). Sendo assim, Lorde considera que é importante falar verdades nas quais se acredita, ensinar através das vivências, "porque somente assim podemos sobreviver, participando de um processo de vida criativo e contínuo, que é o crescimento" (LORDE, 2020a, p. 44). Uma literatura escrita por mulheres negras, permeada pelas vivências de uma 
comunidade, é uma escrita que dá vida, é uma escrita de sobrevivência.

Em “A transformação do silêncio em linguagem e ação", Audre Lorde diz que passou "a acreditar, com uma convicção cada vez maior, que o que me é mais importante deve ser dito, verbalizado e compartilhado, mesmo que eu corra o risco de ser magoada ou incompreendida" (LORDE, 2020a, p. 41). Nesse ensaio, a autora demonstra que a visibilidade e a vulnerabilidade, por mais que deem medo, são fontes de muita força, "porque a máquina vai tentar nos reduzir a pó de qualquer maneira, quer falemos, quer não" (LORDE, 2020a, p. 43). Lorde, então, questiona: "Quais são as palavras que você ainda não tem? O que você precisa dizer?", e afirma que seus silêncios nunca a protegeram: "Meus silêncios não me protegeram. Seu silêncio não vai proteger você” (LORDE, 2020a, p. 42). Para a autora, não é a vulnerabilidade que imobiliza as pessoas, mas os silêncios. Falar, se expor, mostrar as vulnerabilidades e os medos é algo que nos move. E a poesia pode ser revolucionária justamente por nos mover, mesmo que isso envolva lidar com emoções difíceis de serem suportadas. Pois, para a Audre Lorde, "à medida que os conhecemos e os aceitamos, nossos sentimentos, e o ato de explorá-los com honestidade, se tornam santuários e campos férteis para as ideias mais radicais e ousadas." (LORDE, 2020a, p. 37). Segundo Sara Ahmed (2015),

[Audre Lorde] nos convidou a permanecer com os ressentimentos: recusar sermos silenciadas pela raiva, falar com raiva, habitar o desespero de saber que o mundo que almejamos não será alcançado em nosso tempo de vida. Ela nos convidou a habitar a esperança de transmitir esse objetivo a outros. A luta pode ser calorosa; pode haver bondade e paciência na sobrevivência. Lorde nos mostrou que a sobrevivência é um projeto radical para aqueles que "não foram feitos para sobreviver". (AHMED, 2015, p. xii, tradução minha).

A esperança é uma emoção importante não só nas práticas de escrevivência como também nas práticas feministas como um todo. Ao analisar a conexão entre a esperança e os vínculos feministas, Sara Ahmed aponta que "é no presente que os corpos dos sujeitos estremecem com a expectativa do que é diferente; [...]. O momento da esperança é quando o "ainda não" nos deixa uma impressão no presente, de modo que devemos agir politicamente para transformá-lo em nosso futuro." (AHMED, 2017, p. 279, tradução minha). A autora continua: "Se a esperança nos deixa uma impressão no presente, [...], ela exige que atuemos no presente em vez de apenas esperar por um futuro que sempre está diante de nós." (AHMED, 2020, p. 279, tradução minha). Em "A poesia não é um luxo", ensaio publicado pela primeira vez na revista Chrysalis: A Magazine of Female Culture, em 1977, Audre Lorde nos convida a pensar na poesia como uma estratégia de esperança, de sobrevivência para as 
mulheres. Mais do que isso, para as mulheres, a poesia

[...] é uma necessidade vital da nossa existência. Ela cria o tipo de luz sob o qual baseamos nossas esperanças e nossos sonhos de sobrevivência e mudança, primeiro como linguagem, depois como ideia, e então como ação mais tangível. É da poesia que nos valemos para nomear o que ainda não tem nome, e que só então pode ser pensado. Os horizontes mais longínquos das nossas esperanças e dos nossos medos são pavimentados pelos nossos poemas, esculpidos nas rochas que são nossas experiências diárias (LORDE, 2020a, p. 37).

Assim, para Audre Lorde, é através da poesia que se constrói a esperança. Essa poesia que "não é apenas sonho e imaginação; ela é o esqueleto que estrutura nossa vida." (LORDE, 2020a, p. 38). Evocando sua ancestralidade na figura da mãe negra, Audre Lorde subverte a hierarquização ocidental da razão sobreposta à emoção, aludindo à liberdade: "Os patriarcas brancos nos disseram: "Penso, logo existo". A mãe negra dentro de cada uma de nós - a poeta - sussurra em nossos sonhos: "Sinto, logo posso ser livre”. A poesia cria a linguagem para expressar e registrar essa demanda revolucionária, a implementação da liberdade" (LORDE, 2020a, p. 38). Ainda sobre a dicotomia entre razão e emoção, Audre Lorde continua:

[...] esperava-se que os sentimentos se submetessem ao pensamento assim como era esperado das mulheres que se submetessem aos homens. Mas as mulheres sobreviveram. Como poetas. E não existem novas dores. Já as sentimos antes. E escondemos esse fato no mesmo lugar onde temos escondido nosso poder. As dores emergem dos nossos sonhos, e são os nossos sonhos que apontam o caminho para a liberdade. Aqueles sonhos que se tornam realizáveis por meio dos nossos poemas, que nos dão a força e a coragem para ver, sentir, falar e ousar. (LORDE, 2020a, p. 39).

Dar vazão ao sentir, e não só ao pensar, faz parte, então, da escrevivência. As emoções, as dores - que não são novas - e tantos outros afetos fazem parte da poesia de mulheres, de sua sobrevivência. Uma epistemologia para uma crítica feminista da literatura lésbica negra deve levar em consideração os sonhos que se tornam realizáveis através da escrita, quando mulheres negras lésbicas ousam falar, desafiando o silêncio imposto a elas.

\section{CONSIDERAÇÕES FINAIS}

Neste artigo, busquei expor o que considero que sejam as contribuições de Audre Lorde para uma epistemologia da crítica feminista à literatura lésbica negra, bem como aludir a textos clássicos da teoria literária feminista e da teoria literária lésbica para a construção 
dessa "nova" epistemologia. A literatura negra lésbica pode ser um instrumento de libertação para mulheres negras lésbicas, pois explorar a potência da escrita para essas mulheres é justamente ampliar as possibilidades de subversão e resistência. Os textos de Audre Lorde apontam para sua materialidade: é uma mulher, negra, lésbica, mãe, poeta e guerreira que assina os ensaios, os poemas, os livros. Como Lorde demonstrou, não é fácil ou sequer possível separar a literatura da vida, nem mesmo a poesia da teoria feminista.

Pensando na zona selvagem como um local abstrato onde é possível construir uma cultura que desafia os limites patriarcais, colocando as mulheres no centro, Adrienne Rich (CAMARGO, 2018) sonha com uma língua em comum que possa confrontar o cânone literário masculino com uma linguagem feminista que permita narrar o amor entre mulheres. Nesse sentido, a tomada do poder do erótico por parte das mulheres pode ser visto como potência para a construção de uma escrita das mulheres, operando contra o silêncio imposto. Audre Lorde afirmou que se colocar contra o silêncio é algo que nos move, e a poesia pode ser revolucionária justamente por nos mover (LORDE, 2020a). Para a autora, a retomada do erótico como uma linguagem pode driblar esses silêncios.

Audre Lorde (2020a), assim como Conceição Evaristo (2007), propõe o intenso comprometimento da escrita com a vida. A escrevivência se faz presente na escrita de Lorde, e deve integrar a epistemologia de uma crítica feminista da literatura lésbica negra. Através da potência que emana do erótico como linguagem e da escrevivência como resistência, podemos refletir sobre a literatura lésbica negra como uma importante prática de registro da memória e da história dessas mulheres.

Nesse sentido, vale apontar que a literatura negra lésbica pode ser uma estratégia de esperança. Como afirmou Sara Ahmed (2017), “quando pensamos na questão sobre o futuro do feminismo, devemos também prestar atenção aos legados do passado feminista; [...] a pergunta sobre o futuro é afetiva; é uma pergunta esperançosa sobre o que ainda podemos nos tornar, assim como o medo pelo que podemos nos tornar" (p. 278, tradução minha). Enfrentando o medo e o silêncio, assumindo suas vulnerabilidades, Audre Lorde dá peso à sua escrita, e escreve como quem tem a "esperança como modo de vida que nos impulsiona, de olhos abertos e temerosa, disposta a todas as batalhas da vida" (LORDE, 2020b, s/p.).

\section{REFERÊNCIAS BIBLIOGRÁFICAS}

AHMED, Sara. Foreword. In: BROECK, Sabine; BOLAKI, Stella. Audre Lorde's transnational legacies. Boston: University of Massachusetts Press, 2015. p. ix-xiii. 
AHMED, Sara. Vínculos feministas. In: AHMED, Sara. La política cultural de las emociones. Coyoacán, México: Universidad Nacional Autónoma de México, Centro de Investigaciones y Estudios de Género, 2017. p. 255-286.

BEREANO, Nancy K. Introdução. In: LORDE, Audre. Irmã Outsider. Ensaios e conferências. Tradução de Stephanie Borges. Belo Horizonte: Autêntica Editora, 2020. p. 611.

CAMARGO, Sarah Valle. O sonho de uma língua comum: a tradição segundo Adrienne Rich. Revista Criação \& Crítica, n. 20, p. 56-77, 20 abr. 2018.

CERQUEIRA, Vanessa. Corpo, lesboafetividade e violência: uma análise sobre o conto "Os olhos verdes de Esmeralda". In: ALVES, Bárbara E. R. A.; FERNANDES, Felipe B. M.. Pensamento lésbico contemporâneo: decolonialidade, memória, família, educação, política e artes. 1. ed. Florianópolis: Tribo da Ilha, 2021. p. 437-443.

DA LUZ, Agatha L. E.; DE MIRANDA, Juliana D.; SILVA, Aiana H. S. Afeto e (Des) Humanização: a literatura negra lésbica como instrumento de luta. Gênero na Amazônia: Dossiê Mulheres, Política e Poder. n. 15, p. 133-143, 2019.

EVARISTO, Conceição. Da grafia-desenho de minha mãe; um dos lugares de nascimento de minha escrita. In: ALEXANDRE, Marcos Antônio (Org.). Representações performáticas brasileiras. Belo Horizonte: Mazza Edições, 2007, p. 16-21.

GOMYDE, Monalisa A. C. Existe uma Cultura Literária Lésbica? Caderno Espaço Feminino, Uberlândia, MG, v.34, n.1, jan./jun. 2021, p. 427-447.

LORDE, Audre. Irmã outsider: Ensaios e conferências. Tradução de Stephanie Borges. Belo Horizonte: Autêntica Editora, 2020a.

LORDE, Audre. Sou sua irmã: Escritos reunidos e inéditos. Tradução de Stephanie Borges. E-book (não-paginado). São Paulo: Ubu Editora, 2020 b.

PONTES, Isadora A. Narrativas de mulheres e da lesbianidade: discursos do "outro lugar". Revista Criação \& Crítica, n. 20, p. 20-39, 20 abr. 2018.

RICH, Adrienne. Heterossexualidade compulsória e existência lésbica. Bagoas-Estudos gays: gêneros e sexualidades, v. 4, n. 05, 2010.

RICH, Adrienne. The Will to Change. New York: W.W. Norton \& Company, 1971.

ROWELL, Charles. H.; LORDE, Audre. Above the Wind: An Interview with Audre Lorde. Callaloo, v. 23, n. 1, p. 52-63, 2000.

SHOWALTER, Elaine. A crítica feminista no território selvagem. In: HOLLANDA, Heloísa Buarque de. Tendências e impasses: o feminismo como crítica da cultura. Rio de Janeiro: Rocco. p. 23-57.

WITTIG, Monique. As Guerrilheiras. São Paulo: Ubu Editora, 2019. 
Revista de Literatura,

História e Memória
Unioeste /Cascavel - p. 159-175

V. 17 - N. 30 - 2021

Recebido: 26/08/2021

Aceito: 25/01/2022 